\title{
GATA4 transcription factor is required for ventral morphogenesis and heart tube formation
}

\author{
Chay T. Kuo, Edward E. Morrisey, Roshani Anandappa, Kirsten Sigrist, Min M. Lu, \\ Michael S. Parmacek, Claire Soudais, and Jeffrey M. Leiden ${ }^{1}$ \\ Departments of Medicine and Pathology and Committee on Genetics, The University of Chicago, \\ Chicago, Illinois 60637 USA
}

\begin{abstract}
Previous studies have suggested that the GATA4 transcription factor plays an important role in regulating mammalian cardiac development. In the studies described in this report we have used gene targeting to produce GATA4-deficient mice. Homozygous GATA4-deficient $\left(\right.$ GATA4 $\left.^{-1}\right)$ mice died between 8.5 and 10.5 days post coitum (dpc). GATA4 ${ }^{-/-}$embryos displayed severe defects in both rostral-to-caudal and lateral-to-ventral folding, which were reflected in a generalized disruption of the ventral body pattern. This resulted in the defective formation of an organized foregut and anterior intestinal pore, the failure to close both the amniotic cavity and yolk sac, and the uniform lack of a ventral pericardial cavity and heart tube. Analysis of cardiac development in the $\mathrm{GATA4}^{-/-}$mice demonstrated that these embryos developed splanchnic mesoderm, which differentiated into primitive cardiac myocytes that expressed contractile proteins. However, consistent with the observed defect in ventral morphogenesis, these GATA4 ${ }^{-1-}$ procardiomyocytes failed to migrate to the ventral midline to form a linear heart tube and instead formed aberrant cardiac structures in the anterior and dorsolateral regions of the embryo. The defect in ventral migration of the $\mathrm{GATA4}^{-/-}$procardiomyocytes was not cell intrinsic because $\mathrm{GATA4}^{-/-}$cardiac myocytes and endocardial cells populated the hearts of $\mathrm{GATA4}^{-1-}-\mathrm{C} 57 \mathrm{BL} / 6$ chimeric mice. Taken together, these results demonstrated that GATA4 is not essential for the specification of the cardiac cell lineages. However, they define a critical role for GATA4 in regulating the rostral-to-caudal and lateral-to-ventral folding of the embryo that is needed for normal cardiac morphogenesis.
\end{abstract}

[Key Words: GATA4; gene targeting; precardiac mesoderm; ventral morphogenesis]

Received February 25, 1997; revised version accepted March 14, 1997.

The heart is the first functional organ formed during higher vertebrate development. A beating heart is required to facilitate the exchange of nutrients between mother and fetus beginning at 8.5 days post coitum (dpc) of embryonic development in the mouse. The formation of the heart is a complex process involving the specification of multiple cell lineages including cardiac myocytes, endocardial cells, and vascular endothelial and smooth muscle cells, as well as multiple morphogenic events required for the assembly of the mature fourchambered structure. In the mouse, the earliest stage of cardiac development involves the formation of the horseshoe-shaped intraembryonic coelom that splits the mesoderm into splanchnic and somatic components at $\sim 7$ dpc (Fig. 1) (Kaufman and Navaratnam 1981; DeRuiter et al. 1992). A portion of the splanchnic mesoderm anterior and anterolateral to the head fold then differentiates into cuboidal precardiac mesoderm therein referred

${ }^{1}$ Corresponding author.

E-MAIL jleiden@medicine.bsd.uchicago.edu; FAX (773) 702-1385. to as procardiomyocytes) that expresses contractile proteins but do not assemble myofibers nor contract. Shortly thereafter, the embryo undergoes two important morphogenic events: (1) the rostral-to-caudal folding of the head and associated precardiac mesoderm that positions the precardiac mesoderm caudal to the head fold, and (2) the lateral-to-ventral folding or migration and subsequent midline fusion of the precardiac splanchnic mesoderm (Fig. 1) (Moore and Persaud 1993; Kaufman 1995). Over the next day of embryonic development the ventral precardiac splanchnic mesoderm expands into a linear heart tube lined by endocardium and becomes attached to the dorsal wall of the pericardial cavity by a dorsal mesocardium (Kaufman and Navaratnam 1981; DeRuiter et al. 1992). Between 8 and $11 \mathrm{dpc}$ this primitive heart tube undergoes looping and septation to generate the mature four-chambered cardiac structure (Kaufman 1995; Olson and Srivastava 1996).

Recent studies have identified several transcription factors that are required for cardiac looping and late cardiac morphogenesis. These include Nkx2.5 (Komuro and 


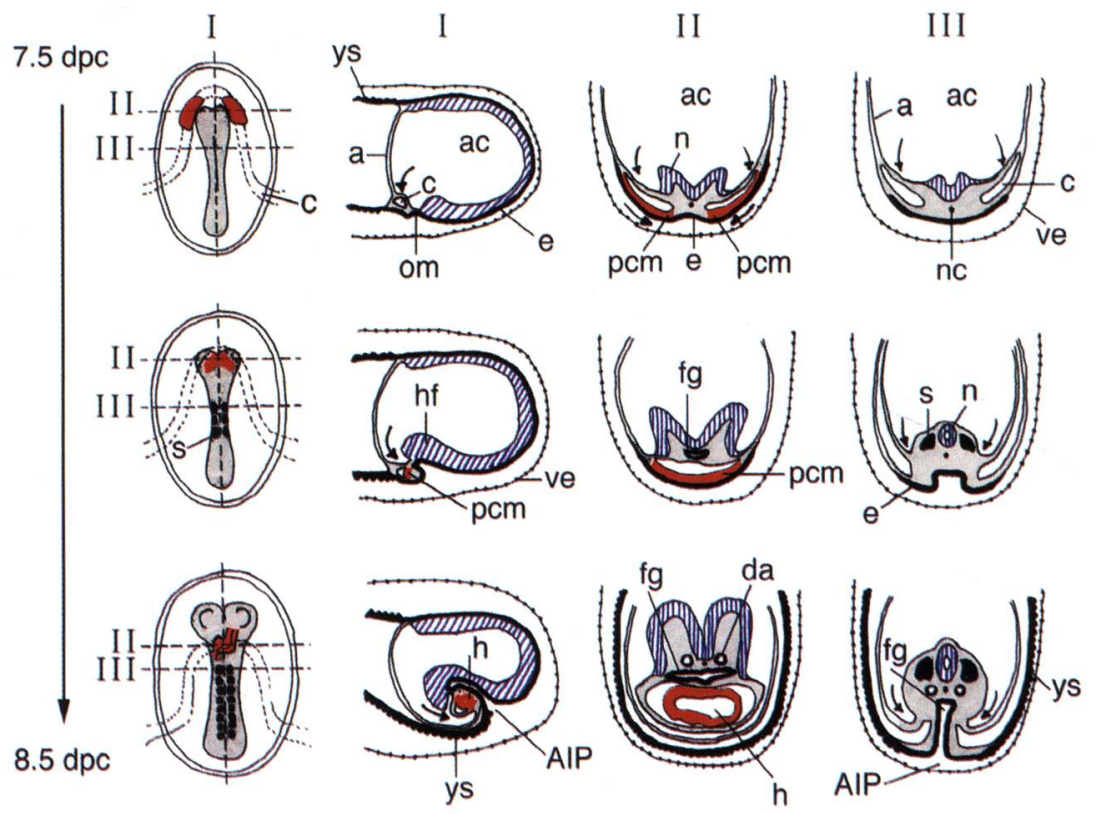

Figure 1. Schematic representation of heart tube formation during murine embryogenesis. (Left) Dorsal view of the developing mouse embryo between 7.5 (top) and 8.5 (bottom) dpc. (I) Midline sagittal sections of the same embryos. (II) Transverse sections through the same embryos at the level of the developing heart. (III) Transverse sections through the same embryos at the level of the developing foregut. The precardiac mesoderm and linear heart tube are shown in red, the somites are shown in solid black. The neural tube is shown by the vertical blue shading. The arrows indicate the direction of embryo folding. (a) Amnion; (ac) amniotic cavity; (AIP) anterior intestinal pore; (c) intraembryonic coelomic cavity; (da) dorsal aorta; (e) embryonic endoderm; (fg) foregut; (h) heart; (hf) head fold; (n) neural fold; (nc) notocord; (om) oropharyngeal membrane; $(\mathrm{pcm})$ precardiac mesoderm; (s) somite; (ve) visceral endoderm; (ys) yolk sac.
Izumo 1993; Lints et al. 1993; Lyons et al. 1995), a homeodomain transcription factor related to the Drosophila protein tinman (Bodmer 1993), as well as the basic helix-loop-helix (bHLH) transcription factors dHAND (deciduum, heart, autonomic nervous system, and neural crest derivatives) and eHAND (extraembryonic tissue, heart, autonomic nervous system, and neural crest derivatives) (Srivastava et al. 1995). In contrast, relatively little is known about the transcriptional programs that control cardiac myocyte lineage determination and early cardiac morphogenesis.

The GATA family of vertebrate transcription factors is comprised of six members (GATA1 through GATA6), each of which contains a highly related Cys- $\mathrm{X}_{2}-\mathrm{Cys}^{-} \mathrm{X}_{17^{-}}$ Cys- $\mathrm{X}_{2}$-Cys type IV zinc finger DNA-binding domain / $\mathrm{Si}$ mon 1995). GATA proteins bind as monomers to the consensus sequence WGATWR (Ko and Engel 1993; Merika and Orkin 1993; Crossley et al. 1995). Mammalian GATA family members can be divided into two subfamilies on the basis of their structures and their patterns of expression. GATA1 (Evans and Felsenfeld 1989; Tsai et al. 1989), GATA2 (Lee et al. 1991; Dorfman et al. 1992), and GATA3 (Ho et al. 1991; Ko et al. 1991) belong to one subfamily and are expressed in overlapping patterns in hematopoietic cells. Gene-targeting experiments have demonstrated the importance of these factors for the development of specific hematopoietic lineages. GATAl is required for the development of the erythroid lineage (Penvy et al. 1991), GATA2 for the development or survival, or both, of the pluripotent hematopoietic stem cell (Tsai et al. 1994), and GATA3 for the differentiation of early $\mathrm{T}$-cell progenitors (Ting et al. 1996). GATA4 (Arceci et al. 1993; Kelley et al. 1993), GATA5 (Laverriere et al. 1994, Morrisey et al. 1997), and GATA6 (Laverriere et al. 1994, Morrisey et al. 1996) represent a second subfamily of mammalian GATA proteins. Members of this subfamily share two structurally related amino-terminal transcriptional activation domains and are expressed in partially overlapping patterns in the visceral endoderm, and in the developing heart, gut, and smooth muscle.

Several lines of evidence suggested that GATA4 might play an important role in regulating cardiac development. First, GATA4 is one of the earliest transcription factors expressed in developing cardiac cells with expression detectable in murine precardiac splanchnic mesoderm as early as $7.0 \mathrm{dpc}$ (Arceci et al. 1993; Heikinheimo et al. 1994). By $8-9$ dpc, abundant GATA4 mRNA is present in both the endocardium and myocardium of the folding heart tube, and GATA4 continues to be expressed in cardiac myocytes throughout the life of the animal. Second, functionally important GATA4-binding sites are present in a number of cardiac muscle-specific promoters and enhancers including the cardiac troponin C (cTnC) enhancer (Ip et al. 1994), the $\alpha$-myosin heavy chain ( $\alpha$-MHC) promoter (Molkentin et al. 1994), the atrial naturietic factor (ANF) promoter (Grepin et al. 1994), and the myosin light chain I (MLCI) promoter (Rotter et al. 1991). Overexpression of GATA4 can transactivate several of these promoters in nonmuscle cells (Grepin et al. 1994; Ip et al. 1994; Molkentin et al. 1994). Finally, overexpression of anti-sense GATA4 transcripts in cultured P19 cells has been reported to block cardiac myocyte differentiation in response to dimethyl sulfoxide (Grepin et al. 1995) and injection of GATA4, GATA5, or GATA6 mRNA into Xenopus embryos has been reported to activate ectopic expression of cardiac genes such as $\alpha$-cardiac actin and $\alpha-$ MHC (Jiang and Evans 1996).

Despite these findings, the precise role of GATA4 in cardiac development remained unclear. In the studies described in this report, we have used homologous recombination in murine embryonic stem (ES) cells to produce a targeted mutation of the GATA4 gene. ES cells 
Kuo et al.

containing heterozygous mutations of GATA4 were used to produce GATA4-deficient $\left(G A T A 4^{-/}\right)$mice and ES cells containing homozygous mutations of the GATA4 gene and expressing the bacterial lacZ gene were used to produce $G A T A 4^{-1-}-C 57 B L / 6$ chimeric mice. An analysis of cardiac development in these mice demonstrated that GATA-4 is not required for the specification of the cardiac myocyte or endocardial cell lineages but is necessary for an early step in cardiac morphogenesis (i.e., the rostral-to-caudal and lateral-to-ventral migration of committed procardiomyocytes to form the pericardial cavity and primitive heart tube). Consistent with this finding, GATA4 is also required for other morphogenic processes that are associated temporally and spatially with lateralto-ventral embryo folding including the proper formation of the anterior intestinal pore and foregut and the ventral closure of the amniotic membrane and yolk sac around the embryo. Finally, we show that expression of the closely related transcription factor GATA6 is significantly up-regulated in the GATA4 ${ }^{-1-}$ embryos, suggesting that these two transcription factors may belong to a common developmental pathway and that GATA6 may compensate partially for GATA4 in the $G A T A 4^{-/-}$embryos.

\section{Results}

Generation of $\mathrm{GATA}^{-/-}$mice

To produce a null mutation of the GATA4 gene, we constructed a GATA4-targeting vector in which exon 2, the first coding exon of the gene was replaced with a phosphoglycerokinase (PGK)-neomycin cassette (Fig. 2A). After electroporation of the linearized targeting vector into R1 ES cells, G418- and gancyclovir-resistant ES cell colonies were screened for homologous recombination by Southern blot analysis. Three of the 96 ES cell colonies screened were shown to be homologous recombinants (data not shown). Each of these GATA4 ${ }^{+/}$clones contained a single integration of the targeting vector as determined by Southern blot analysis with a neo probe (data not shown). To obtain GATA4 ${ }^{-/-}$ES cells, two independently derived GATA4 ${ }^{+/-}$ES cell lines were subjected to growth selection in increasing concentrations of G418. Southern blot analyses performed on high concentration G418-resistant ES cell colonies identified 3 of 36 clones as being homozygous for the targeted GATA4 allele (data not shown).

To confirm that we had produced a null mutation with this targeting vector, we performed Northern blot analyses on RNA isolated from in vitro-differentiated GATA4 $^{-1-}$ ES cells. As described previously, high levels of GATA4 mRNA expression were seen after 11-16 days of differentiation of wild-type ES cells into embryoid bodies in vitro (Soudais et al. 1995) (Fig. 2C). In contrast, neither full-length nor truncated GATA4 mRNA was detectable in the in vitro-differentiated GATA4 ${ }^{-1-}$ ES cells using probes derived from both the coding and $3^{\prime}$ untranslated regions of the GATA4 gene (Fig. 2B; data not shown). The lack of a trunctated GATA4 mRNA was confirmed by RT-PCR using primers from exons 3 and 5

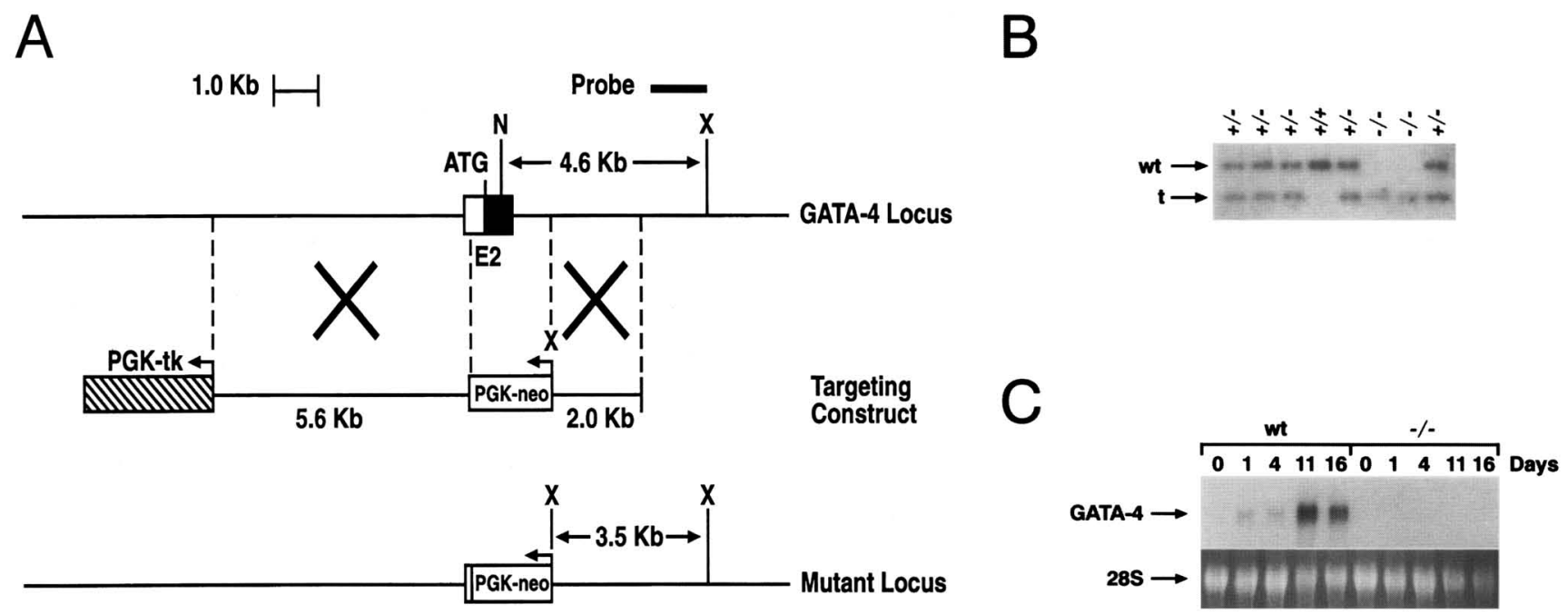

Figure 2. Targeted disruption of the GATA4 gene. (A) Schematic representation of the GATA4 targeting strategy. (Top) Partial restriction endonuclease map of the murine GATA4 locus: Exon 2 (E2) is shown as a box, the coding region is shown in black along with the translational initiation codon (ATG), and the $5^{\prime}$ UTR is in white. Restriction enzymes: (N) NotI; (X) XhoI. (Middle) Structure of the GATA4 targeting constructs containing the herpes simplex virus thymidine kinase (HSV-tk) (tk) and neomycin-resistance (neo) genes under the control of the mouse phosphoglycerate kinase (PGK) promoter. (Bottom) Structure of the targeted GATA4 allele in which the ATG and coding region of the second exon were replaced with the PGK-neo cassette. (B) Southern blot analysis of offspring from a GATA4 $4^{+-} \times \mathrm{GATA4}^{+/-}$mating. NotI-XhoI digestion of 8.5-dpc embryonic DNA hybridized to the genomic probe shown in Fig. 2A. The position of the wild type $(\mathrm{wt})$ and targeted $(\mathbf{t})$ alleles are shown with arrows to the left of the autoradiograph. $(C)$ (Top) Northern blot analysis of GATA4 expression in wild-type $(w t)$ and homozygous $(-/-)$ ES cells after in vitro differentiation. (Bottom) Equal loading and integrity of the RNA samples was confirmed by ethidium bromide staining of the 28S RNA in the gel before transfer to nitrocellulose membranes (28S). 
of the murine GATA4 gene (data not shown). Thus, the targeted ES cells appeared to contain a null mutation, a finding confirmed by the in situ hybridization analyses described below (Fig. 3D).

Three independently derived GATA4 ${ }^{+/-}$ES cell lines were used to generate male chimeric mice, and chimeric males derived from one of these ES cell lines when crossed to C57BL/ 6 females transmitted the targeted allele through the germ line as determined by both offspring coat color and Southern blot analysis (Fig. 2B). $G A T A 4^{+/-}$heterozygous mice were phenotypically normal. They were outbred to wild-type C57BL/6 and CD1 mice, generating heterozygotes that were intercrossed subsequently to generate the $G A T A 4^{-/-}$homozygous mice. The phenotypes of the $G A T A 4^{-/-}$mice were identical on all genetic backgrounds studied. As shown in Table 1, no $G A T A 4^{-/-}$animals were observed among $>100$ live-born offspring from $\mathrm{GATA}^{+/-} \times \mathrm{GATA4}^{+/-}$ matings. Genotyping of 8.5-dpc embryos from $G A T A 4^{+/}$ - $\times \mathrm{GATA4}^{+/-}$matings showed Mendelian segregation of the GATA4 $^{-1-}$ genotype (Fig. 2B and Table 1). Most of these $G A T A 4^{-/-}$embryos were resorbed shortly after 8.5 dpc. However, a small number of $G A T A 4^{-1-}$ embryos were detected at 9.5 and 10.5 dpc. All $G A T A 4^{-/-}$embryos were resorbed by $11.5 \mathrm{dpc}$ (Table 1 ).
Table 1. Genotype of offspring from GATA-4 $4^{+/-} \times$ GATA $-4^{+/-}$matings

\begin{tabular}{lrccc}
\hline Age & $+/+$ & $+/-$ & $-/-$ & Resorbed $^{a}$ \\
\hline $8.5 \mathrm{dpc}$ & $13(24 \%)$ & $30(55 \%)$ & $10(18 \%)$ & $2(3 \%)$ \\
$9.5 \mathrm{dpc}$ & $18(26 \%)$ & $29(43 \%)$ & $4(6 \%)$ & $17(25 \%)$ \\
$10.5 \mathrm{dpc}$ & $18(21 \%)$ & $43(57 \%)$ & $4(5 \%)$ & $19(23 \%)$ \\
$11.5 \mathrm{dpc}$ & $5(23 \%)$ & $11(50 \%)$ & none & $6(27 \%)$ \\
Newborn & $50(36 \%)$ & $89(64 \%)$ & none & none \\
\hline
\end{tabular}

${ }^{a}$ Resorbed embryos could not be genotyped because of extensive necrosis.

\section{Cardiac development in $\mathrm{GATA}^{-/-}$embryos}

Hematoxylin and eosin (H \& E) staining of 8.5-dpc wildtype embryos demonstrated the presence of a wellformed midline ventral heart tube, which was enclosed within a single ventral pericardial cavity (Fig. 3A). By in situ hybridization, the hearts from these 8.5 -dpc wildtype embryos displayed expression of both GATA4 (Fig. 3C) and GATA6 (Fig. 3E) as well as the cardiac-specific markers MHC (Fig. 3G), myosin light chain 2A (MLC2A), and cTnC (data not shown). These wild-type embryos also contained easily identifiable neural folds, foregut, and dorsal aortas (Fig. 3A). Heterozygous
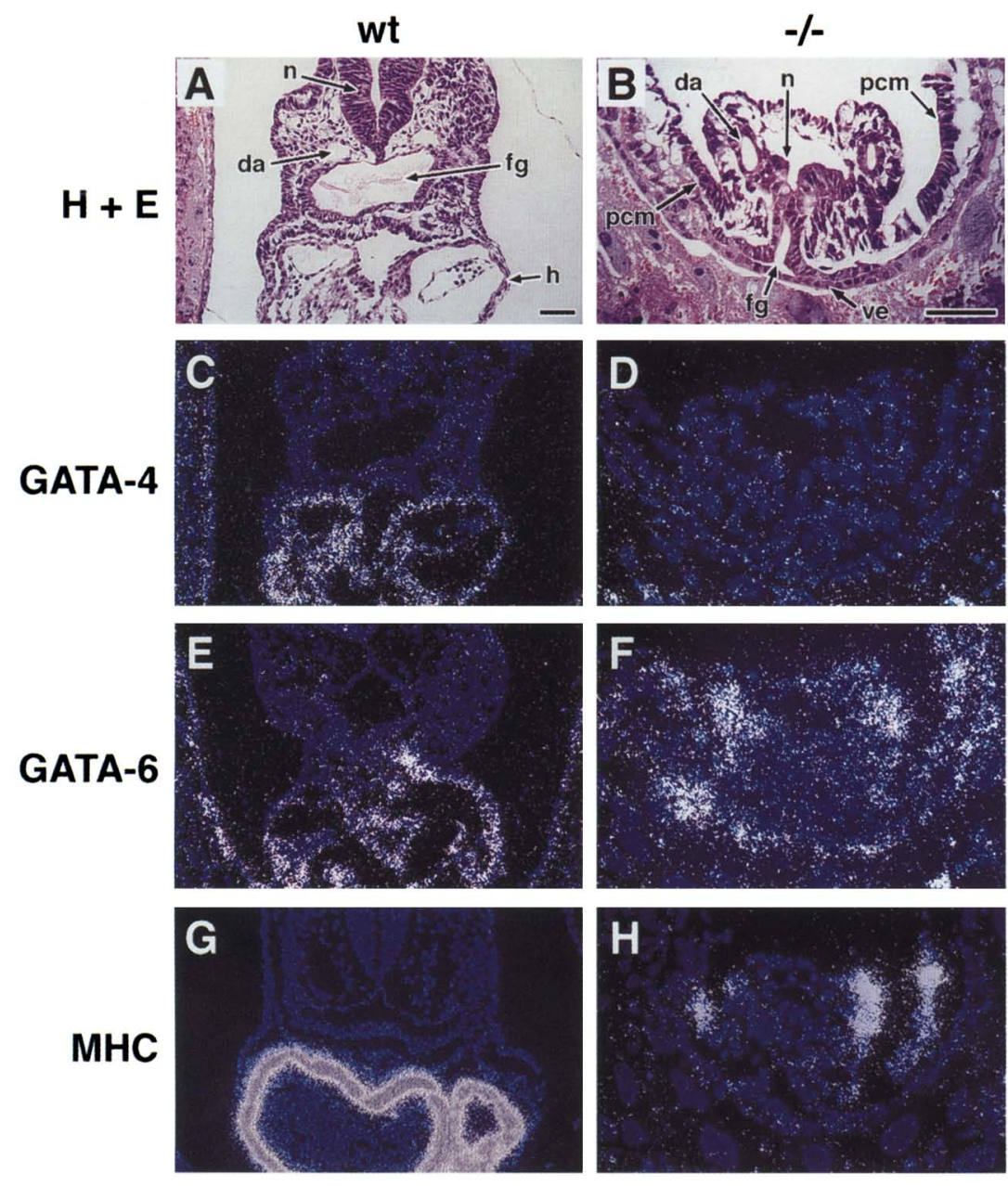

Figure 3. Cardiac defects in 8.5 -dpc GATA4 $4^{-1-}$ embryos. Histological $(A, B)$, and in situ hybridization $(\mathrm{C}-\mathrm{H})$ analyses of $8.5-\mathrm{dpc}$ wild-type (wt) and GATA4 $^{-/-}(-/-)$embryos. (A) $\mathrm{H} \&$ E-stained transverse section of an 8.5dpc wild-type embryo. Note the dorsally located neural tube (n), dorsal aorta (da), foregut $(\mathrm{fg})$, and the ventrally located heart $(\mathrm{h}) .(B)$ $\mathrm{H} \&$ E-stained transverse section of an 8.5-dpc GATA4 $4^{-1-}$ embryo. Note the dorsally located neural tube $(\mathrm{n})$, dorsal aorta (da), ventrally located invaginating foregut $(\mathrm{fg})$, visceral endo$\operatorname{derm}\{$ vel, and laterally located precardiac mesoderm $(\mathrm{pcm}) .(C, D)$ In situ hybridizations using a GATA4 antisense cRNA probe. Note the GATA4 expression in the developing heart tube of 8.5-dpc wild-type embryo and the lack of GATA4 expression in the GATA4 $4^{-/-}$embryo. $\langle E, F\rangle$ In situ hybridizations using a GATA6 antisense cRNA probe. GATA6 is expressed in an overlapping pattern with GATA4 in the developing heart tube and in the visceral endoderm of the wild-type embryo. In the GATA4 $^{-1-}$ embryo, GATA6 is expressed in visceral endoderm, precardiac mesoderm, and in regions surrounding the dorsal aortas lateral to the neural fold. $(G, H)$ In situ hybridizations using an MHC antisense cRNA probe. MHC is expressed in the heart tube of the wild-type embryo and in regions lateral to the neural fold as well as in the precardiac mesoderm of the GATA4 ${ }^{-1-}$ embryo. Different magnifications and photographic exposures of the wild-type and $G A T A 4^{-/-}$embryos were used to ensure adequate visualization of each of the probes in both embryos. Bar, $33 \mu \mathrm{m}$. 
(GATA4 $4^{+/-}$) embryos were indistinguishable from their wild-type littermates (data not shown). In contrast, 8.5dpc $G A T A 4^{-/-}$embryos uniformly lacked a ventral pericardial cavity and heart tube (Fig. 3B). Although the GATA4 $4^{-1-}$ embryos were smaller than age-matched wild-type littermates, the lack of a ventral heart tube did not appear to simply reflect a generalized developmental delay because these embryos contained a dorsally located neural fold and an early invaginating foregut. In addition, they contained correctly positioned dorsal aortas that normally develop between 8.0 and $8.5 \mathrm{dpc}$, after the formation of the ventral heart tube (Fig. 3B).

The lack of a heart tube in the GATA4 $4^{-1-}$ embryos might have reflected either a defect in cardiac myocyte specification or one or more morphogenic defects in heart tube formation. To distinguish these possibilities, we performed in situ hybridization analyses of the GATA4 $^{-1-}$ embryos with GATA4, GATA6, MHC, MLC2A, and cTnC cRNA probes (Fig. 3D,F,H; data not

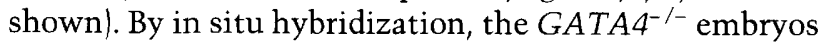
lacked GATA4 expression, confirming the fact that the targeted allele represented a null mutation (Fig. 3D). GATA6, MHC, MLC2A, and cTnC were all expressed in symmetrical crescent-shaped groups of cuboidal mesodermal cells within the lateral walls of the $G A T A 4^{-1-}$ embryos (Fig. 3F,H; data not shown). These structures resembled the folding layers of splanchnic mesoderm in normal 7-dpc embryos. However they had clearly failed to reach the ventral midline and instead remained in the lateral walls of the embryo.

Only $20 \%$ of the GATA4 ${ }^{-1-}$ embryos developed to 10.5 dpc. These embryos were developmentally delayed and contained aberrant cardiac structures located in dorsolateral and anterior regions of the embryo. An example of one such embryo is shown in Figure 4 where it is compared to a wild-type 9.0-dpc embryo. $\mathrm{H} \& \mathrm{E}$ staining of the 9.0-dpc wild-type embryo demonstrated a looped heart tube located posterior to the neural fold and foregut (Fig. 4A). In situ hybridizations demonstrated high-level expression of GATA4, GATA6, Nkx2.5, and MHC in these wild-type heart tubes (Fig. 4C,E,G,I). In contrast, $\mathrm{H}+\mathrm{E}$ staining of $10.5-\mathrm{dpc}$ GATA4 ${ }^{-/-}$embryos demonstrated the presence of a neural fold, somites, and a disorganized body structure lying on the surface of the amnion (Fig. 4B; data not shown). This embryo contained an abnormal unlooped tubular structure anterior and lateral to the head fold, which projected away from the embryo and was clearly located outside of the amniotic cavity. Cells within this tubular structure expressed GATA6 and the cardiac-specific transcripts $\mathrm{Nkx2.5,} \mathrm{MHC}$, MLC2A, myosin light chain 2V (MLC2V), cTnC, cardiac troponin I (cTnI), and ANF (Fig. 4F, H, J; data not shown). As expected, GATA4 expression was not observed in the 10.5-dpc GATA4 ${ }^{-1-}$ embryos (Fig. 4D). Taken together, these studies demonstrated that GATA4 is not required for specification of embryonic procardiomyocytes in the splanchnic mesoderm. However, it does play a critical role in the proper caudal and ventral migration and assembly of these cells into the linear heart tube. In the absence of GATA4, the specified procardiomyocytes re- main in the anterior and dorsolateral areas of the embryo and form single or bilateral aberrant cardiac structures.

\section{GATA4 is not required for the differentiation of mature cardiac myocytes and endocardial cells}

The failure of GATA4 ${ }^{-1-}$ procardiomyocytes to migrate caudally and ventrally to form a heart tube might have reflected an intrinsic defect in the migration of these cells or alternatively, a defective morphogenic signal in the $G A T A 4^{-/-}$embryos. To distinguish these possibilities, we generated GATA4-1- ES cells that expressed the bacterial lac $Z$ reporter gene. These cells were injected subsequently into wild-type C57BL/ 6 blastocysts to generate chimeric embryos. X-gal staining of 10.5 -dpc GATA4 $4^{-1-}-C 57 B L / 6$ chimeric embryos showed that $\beta$-gal ${ }^{+}-\mathrm{GATA}^{-1-}$ ES cells contributed to most tissues of the embryo, including the developing brain, limbs, skeletal muscle, and heart (Fig. 5C). Histological analyses of the chimeric embryos demonstrated contribution of the $\beta$-gal ${ }^{+}-\mathrm{GATA}^{-1-}$ cells to the myocardium and endocardium in both the ventricles and atria of these embryos (Fig. 5D). We also performed electron microscopic analyses on chimeric cardiac myocytes from these embryos. GATA4 $^{-/-}$cells could be distinguished from C57BL $/ 6$ cells by the electron-dense $\mathrm{X}$-gal reaction products that appeared as perinuclear and cytoplasmic granular deposits (Fig. 5E). As shown in Figure 5, F and G, the $\beta$-gal ${ }^{+}-$ GATA4 $^{-1-}$ cardiac myocytes contained easily identifiable cardiac myofibers. Taken together, these results extended the findings from the GATA4 ${ }^{-1-}$ embryos and demonstrated that GATA4 is not required for the differentiation of atrial and ventricular cardiac myocytes or endocardial cells. In addition, they suggested that the GATA4 $^{-1-}$ procardiomyocytes are capable of responding to the morphogenic signals that regulate their caudal and ventral migration and assembly into the linear heart tube.

\section{Yolk sac and visceral endoderm formation in GATA4 $^{-1-}$ embryos}

A previous study has reported that in vitro-differentiated GATA4 ${ }^{-1-}$ ES cells did not express the yolk sac markers alpha fetal protein (AFP) and hepatocyte nuclear factor 4 (HNF4) and failed to form visceral endoderm (Soudais et

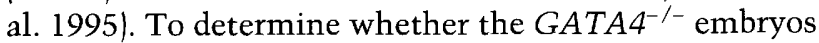
demonstrated similar defects in yolk sac and visceral endoderm development, we performed histological and in situ hybridization analyses of wild-type and $G A T A 4^{-1-}$ embryos. GATA4 ${ }^{-1-}$ embryos contained intact visceral endoderm that expressed high levels of GATA6 transcripts (Fig. 6A-D). Moreover, wild-type and GATA4 ${ }^{-1-}$ embryos contained yolk sacs that expressed high levels of both AFP and HNF4 (Fig. 6E,F; data not shown). However, the GATA4 ${ }^{-1-}$ embryos displayed a defect in closure of the yolk sac surrounding the ventral surface of the embryos (Fig. 6F). This defect is consistent with a generalized defect in rostral-to-caudal and lateral-to-ventral folding of the embryo as the yolk sac is normally 
wt

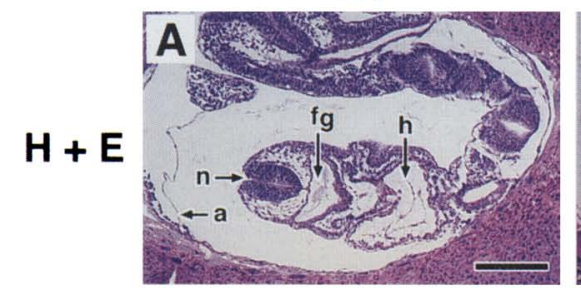

GATA-4
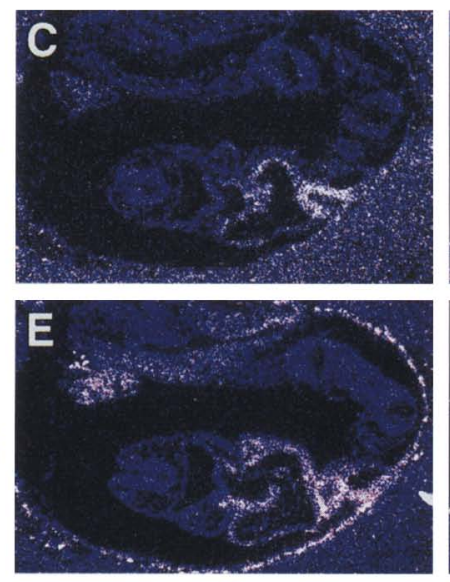

GATA-6

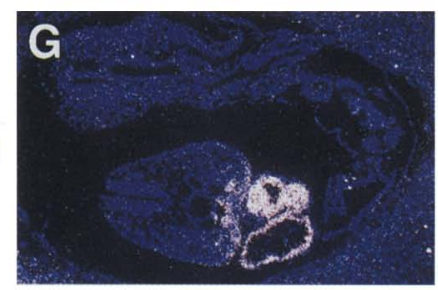

Nkx -2.5

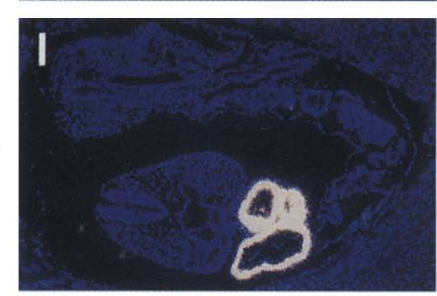

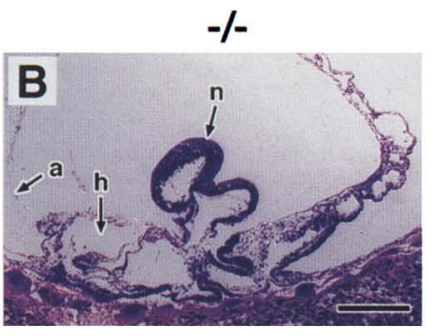
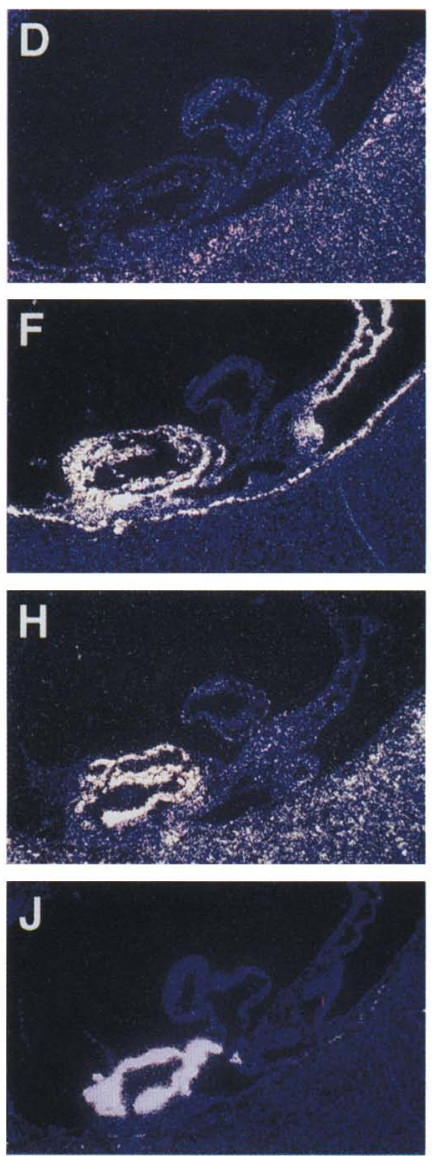

Figure 4. Cardiac defects in 10.5-dpc GATA4 ${ }^{-/-}$ embryos. Histological $(A, B)$, and in situ hybridization $(C-I)$ analyses of 9.0-dpc wild-type $(\mathrm{wt})$ and 10.5-dpc GATA4 ${ }^{-1-}(-/-)$ embryos. $(A, B) \mathrm{H}+\mathrm{E}$ stained sagittal sections. (a) Amnion; (n) neural fold; (fg) foregut; (h) heart. The GATA4 ${ }^{-1-}$ embryo is partially outside of the amniotic cavity and the GATA $4^{-1-}$ heart is located anterior to the head fold. $(C, D)$ In situ hybridizations using a GATA4 antisense cRNA probe. GATA4 is expressed in the heart tube and outflow track of 9.0 -dpc wild-

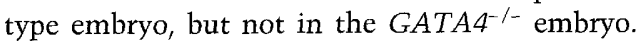
$(E, F)$ In situ hybridizations using a GATA6 antisense cRNA probe. GATA6 is expressed in developing heart tube and outflow track and the visceral endoderm of the wild-type embryo, and in the visceral endoderm, mutant heart, and regions posterior to the neural fold in the GATA4 ${ }^{-/-}$embryo. Different photographic exposures of the wild-type and $G A T A 4^{-/-}$embryos were used to ensure adequate visualization of GATA6 expression in both embryos. $(G, H)$ In situ hybridizations using a Nkx2.5 antisense cRNA probe. Nkx2.5 is expressed in the heart tube of the wild-type embryo and in the mutant heart of the $G A T A 4^{-/-}$ embryo. $\{I, I\}$ In situ hybridizations using a MHC antisense cRNA probe. MHC is expressed in the heart tube of the wild-type embryo and in the $\mathrm{mu}$ tant heart of the GATA4 ${ }^{-/-}$embryo. Bar, $100 \mu \mathrm{m}$. "carried along" with the splanchnic mesoderm as it migrates caudally and ventrally to fuse in the ventral midline. Thus, GATA4 is not required for the formation of the visceral endoderm or yolk sac but it is required for the migration or folding process that produces the normal ventral closure of the yolk sac.

\section{Primitive gut tube formation in $\mathrm{GATA}^{-1-}$ embryos}

The development of the primitive foregut and heart are linked both temporally and spatially during mammalian embryogenesis. The foregut is formed by the same lateral-to-ventral folding process that produces the ventral heart tube (Moore and Persaud 1993; Kaufman 1995). Therefore, it was of interest to examine gut formation in the $G A T A 4^{-1-}$ embryos. H \& E staining of 8.5-dpc wildtype embryos demonstrated the formation of an invaginating foregut and the development of an anterior intestinal pore located ventral to the neural fold (Fig. 7A). By in situ hybridization, the wild-type foregut was positive for the gut epithelial markers HNF3 $\alpha$ and HNF3 $\beta$ (Fig. $7 \mathrm{C}, \mathrm{E})$. In addition, both $\mathrm{HNF} 3 \alpha$ and HNF3 $\beta$ were expressed in basal layers of the neural fold (Fig. 7E). In contrast, 10.5-dpc GATA4-/- embryos displayed a deformed gut structure ventral to the neural fold (Fig. 7B). This deformed gut structure was slitlike as opposed to round in appearance and was fragmented and not connected to an organized anterior intestinal pore (Fig. 7A). In situ hybridizations showed that this structure contained gut epithelial cells expressing HNF3 $\alpha$ and HNF3 $\beta$ (Fig. 7D,F). Thus, as in cardiac development, GATA4 was not required for the lineage determination of gut epithelial cells but instead appeared to be necessary for the normal morphogenesis of the anterior intestinal pore and foregut during embryo folding.

\section{Increased GATA6 expression in the GATA4-1- embryos}

The GATA4 and GATA6 genes have been shown to be 
Kuo et al.

A
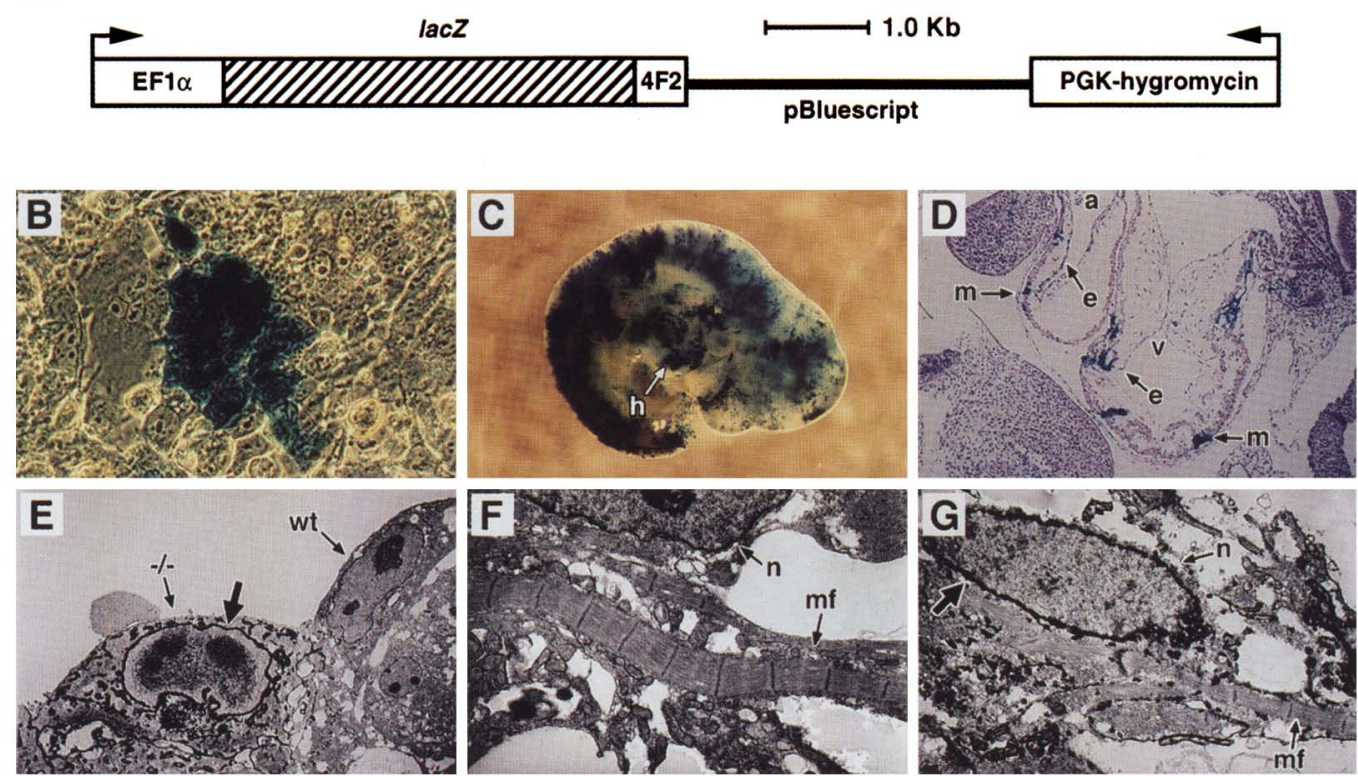

Figure 5. Contribution of $\beta$-gal ${ }^{+}-\mathrm{GATA}^{-/-}$ES cells to the hearts of $G A T A 4^{-/-}-C 57 B L / 6$ chimeric embryos. (A) Schematic representation of the lac Z expression vector that contains the EF1 $\alpha$ promoter (EF1 $\alpha$ ) and 4F2 heavy chain first intron enhancer (4F2) driving transcription of lacZ as well as a PGK-hygromycin cassette. $(B) \mathrm{X}$-gal staining of GATA4 ${ }^{-1}$ ES cells transfected stably with the $1 a c Z$ expression vector. Note the blue ES cell colony growing on a monolayer of nontransfected fibroblasts. $(C)$ X-gal staining of a 10.5-dpc $\beta$-gal ${ }^{+}-\mathrm{GATA}^{-/-}$C $57 \mathrm{BL} / 6$ chimeric embryo showing blue cells in all areas of the embryo including the developing heart (h). (D) Histological analysis of $\beta-g a 1^{+}-G A T A 4^{-/-}$C57BL $/ 6$ chimeric embryo. $\beta-\mathrm{Gal}^{+}-\mathrm{GATA}^{-/-}$cardiac myocytes (m) and endocardial cells (e) are present in both the atrium $(\mathrm{a})$ and the ventricle $(\mathrm{v}) .(E-G)$ Electron microscopic analysis of myocardium in a $\beta-g a 1^{+}-G A T A 4^{-/-}-$ C57BL/6 chimeric embryo. (E) Note the wild-type cardiac myocyte $(\mathrm{wt})$ next to a $\beta$-gal ${ }^{+}$-GATA4 ${ }^{-/-}$cardiac myocyte $(-/-)$. $(F, G)$ Note the cardiac contractile myofibers $(\mathrm{mf})$ in both wild-type $(F)$ and $\beta$-gal ${ }^{+}-\mathrm{GATA} 4^{-1-}(\mathrm{G})$ cardiac myocytes. The thick arrows point to the electron-dense crystalloid X-gal reaction products surrounding the nuclei (n) in the $\beta$-gal ${ }^{+}-\mathrm{GATA}^{-/-}$cardiac myocytes.

coexpressed developmentally in the heart, gut, and visceral endoderm during murine embryogenesis (Morrisey et al. 1996). In addition, the GATA6 gene is expressed in tissue-restricted subsets of smooth muscle cells (Morrisey et al. 1996). Therefore, it was of interest to compare the patterns of GATA6 expression in wild-type and GATA4 $4^{-1}$ embryos. As shown in Figure $8, \mathrm{~A}$ and $\mathrm{B}$, $G A T A 4^{-1-}$ embryos expressed significantly higher levels of GATA6 than their wild-type control littermates in both the extraembryonic membranes and cardiac myocytes. Increased GATA6 expression was observed in both 8.5- and 10.5-dpc GATA4 ${ }^{-1-}$ embryos. Of note, GATA6 overexpression cannot be appreciated fully in the 8.5-dpc GATA $4^{-1-}$ embryo shown in Figure $3 \mathrm{~F}$ because different magnifications and photographic exposures were used in Figures 3, E and F. GATA6 was also shown to be expressed aberrantly at high levels along the entire body wall posterior to the head fold in the 10.5-dpc GATA4 ${ }^{-/-}$ embryos (Fig. 8A,B). Finally, overexpression of GATA6 was also seen after in vitro differentiation of the GATA4 ${ }^{-/-}$ES cells. By Northern blot analysis, the GATA4 $^{-1-}$ ES cells expressed significantly increased levels of GATA6 transcripts as compared to wild-type ES cells after 11 days of liquid culture in vitro (Fig. 8C). In contrast, GATA5, which is expressed in a unique temporally and spatially restricted pattern in the developing heart was not overexpressed in either the $\mathrm{GATA4}^{-/-} \mathrm{em}$ bryos or ES cells (data not shown).

\section{Discussion}

In the studies described in this report, we have used gene targeting to examine the role of the GATA4 transcription factor in mouse development. Homozygous GATA4 deficiency resulted in an embryonic lethal phenotype between 8.5 and $10.5 \mathrm{dpc}$. GATA4-deficient embryos developed visceral endoderm and a yolk sac as well as a neural tube, somites, and dorsal aortas. However, they displayed severe growth retardation and a disorganized ventral body pattern. These embryos uniformly lacked a ventral pericardial cavity and heart tube and instead, contain abnormal cardiac structures located in the anterior and dorsolateral areas of the embryo. In addition, they failed to develop an organized anterior intestinal pore and foregut. Taken together, our findings demonstrated that (1) GATA4 is not required for the specification of the cardiac cell lineages, (2) GATA4 is necessary for the normal rostral-tocaudal and lateral-to-ventral folding of the embryo that produces the pericardial cavity, the heart tube, the foregut, and closure of the yolk sac, (3) the defect in heart formation in the $G A T A 4^{-/-}$embryos is probably not intrinsic to the procardiomyocytes, and (4) GATA4 and GATA6 may belong to a common developmental pathway and, as such, may play partially redundant roles in cardiac and gut formation during mammalian embryogenesis. 


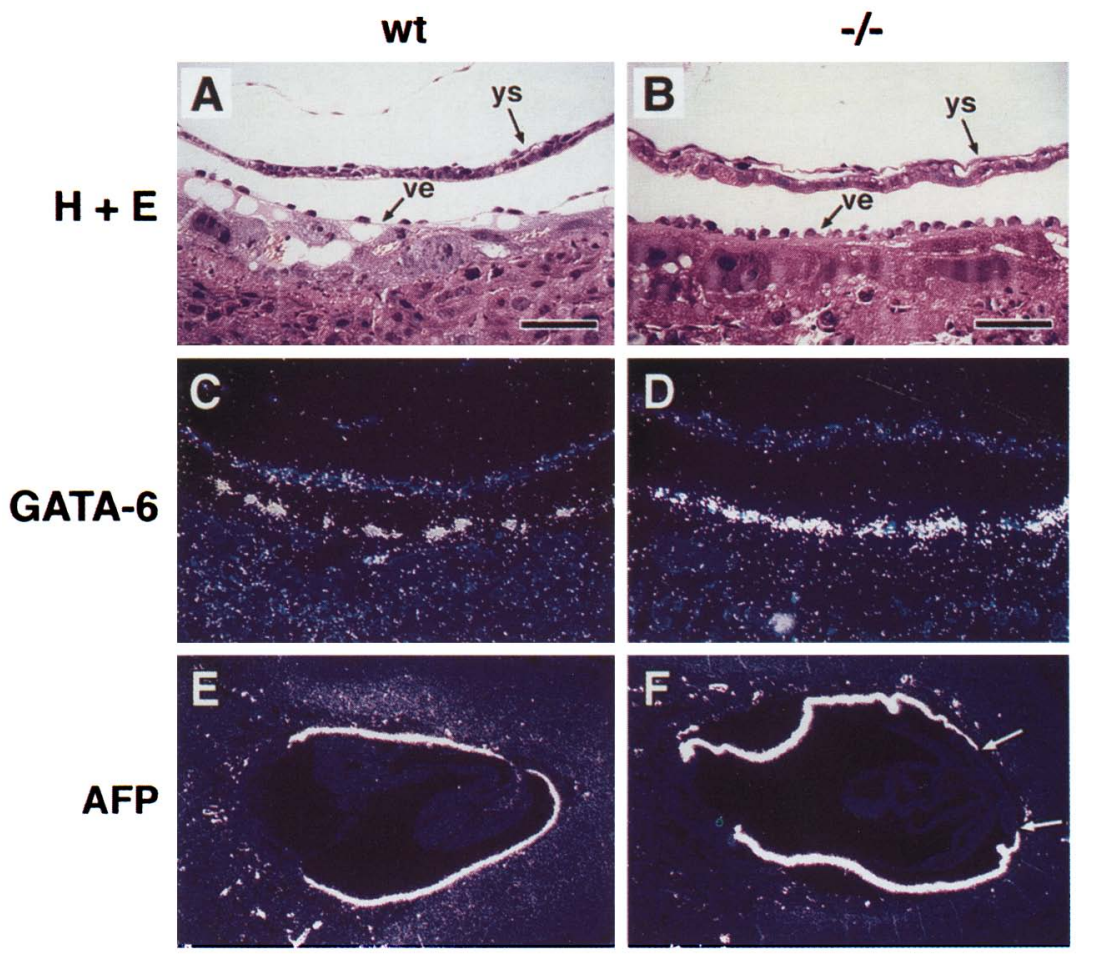

Figure 6. Yolk sac and visceral endoderm formation in the GATA4 ${ }^{-/-}$embryo. Histological $(A, B)$, and in situ hybridization $(C-F)$ analyses of 9.0-dpc wild-type (wt) and 10.5-dpc GATA4 $4^{-/-}(-/-)$embryos. $(A, B) \mathrm{H}$ \& E-stained cross sections. (ve) Visceral endoderm, (ys) yolk sac. $\{C, D\rangle$ In situ hybridizations using a GATA6 antisense cRNA probe. GATA6 is expressed in the visceral endoderm of both the wild-type and GATA4 ${ }^{-1-}$ embryos. Different photographic exposures of the wild-type and GATA4 $4^{-1-}$ embryos were used to ensure adequate visualization of GATA6 expression. $(E, F)$ In situ hybridizations using an AFP antisense cRNA probe. High-level AFP expression is seen in the yolk sacs of both the wild-type and GATA4 $^{-1-}$ embryos. The arrows mark incomplete closure of yolk sac around ventral structures of the GATA4 $^{-/-}$embryos. Bar, $33 \mu \mathrm{m}$.

\section{The role of GATA4 in yolk sac and visceral endoderm development}

Previous in vitro studies suggested that GATA4 is required for the normal development of the visceral endoderm and yolk sac (Soudais et al. 1995). Therefore, it was of interest that the GATA4 $4^{-1-}$ embryos developed both visceral endoderm and yolk sacs. These histological findings were confirmed by in situ hybridization analyses that demonstrated high-level expression of the yolk sac markers AFP and HNF4, as well as the visceral endoderm marker GATA6 in the 10.5-dpc GATA4 ${ }^{-/-}$extraembryonic membranes. As discussed below, it remains possible that GATA4 is important for visceral endoderm and yolk sac formation, but that GATA6 is able to compensate for GATA4 in vivo but not in vitro. Nevertheless, our results demonstrate directly that normal visceral endoderm and yolk sac can form in the absence of GATA4 in the developing vertebrate embryo. Despite the formation of both visceral endoderm and yolk sacs in the $G A T A 4^{-1-}$ embryos, we observed a defect in the ventral closure of the yolk sac in these embryos, which likely reflected the defects in rostral-to-caudal and lateral-to-ventral folding seen in the absence of GATA4.

\section{The role of GATA4 in cardiac development}

Previous studies have suggested that GATA4 might be an important regulator of cardiac myocyte lineage determination (Grepin et al. 1995). However, our results demonstrate that GATA4 is not required either for the specification of committed cardiac myocyte progenitors within the splanchnic mesoderm or for the differentiation of atrial or ventricular cardiac myocytes and endocardial cells. In contrast, GATA4 does appear to be required for the proper assembly of the ventral heart tube during murine embryogenesis. In this sense, GATA4 is distinct from Nkx2.5, dHAND, and eHAND, which are each required for the later looping stages of cardiac morphogenesis (Lyons et al. 1995; Srivastava et al. 1995). Interestingly, $\mathrm{Nkx} 2.5$ is expressed normally in the $G A T A 4^{-1-}$ embryos suggesting that it is not regulated directly by GATA4.

The mechanisms by which GATA4 regulates early cardiac morphogenesis remain unclear. It seems unlikely that the observed defects in cardiac morphogenesis in the $G A T A 4^{-1-}$ embryos simply reflected a generalized developmental delay because these embryos were able to form structures such as the dorsal aortas and somites that develop normally subsequent to ventral heart tube formation during murine embryogenesis. Instead, the phenotype is consistent with specific defects in the rostral-to-caudal and lateral-to-ventral folding of the embryo, which normally occurs $\sim 7 \mathrm{dpc}$ to form the pericardial cavity, the heart tube, and the foregut (Fig. 9) (Moore and Persaud 1993; Kaufman 1995). These folding events likely reflect the differential proliferation and migration of the precardiac splanchnic mesoderm and associated endoderm. In the absence of GATA4, the splanchnic mesoderm failed to migrate to the ventral midline and form the pericardial cavity and heart tube. Instead, these cells formed aberrant cardiac structures in the anterior and dorsolateral regions of the embryo. It is clear from work in the developing chick that failure of ventral fusion of 


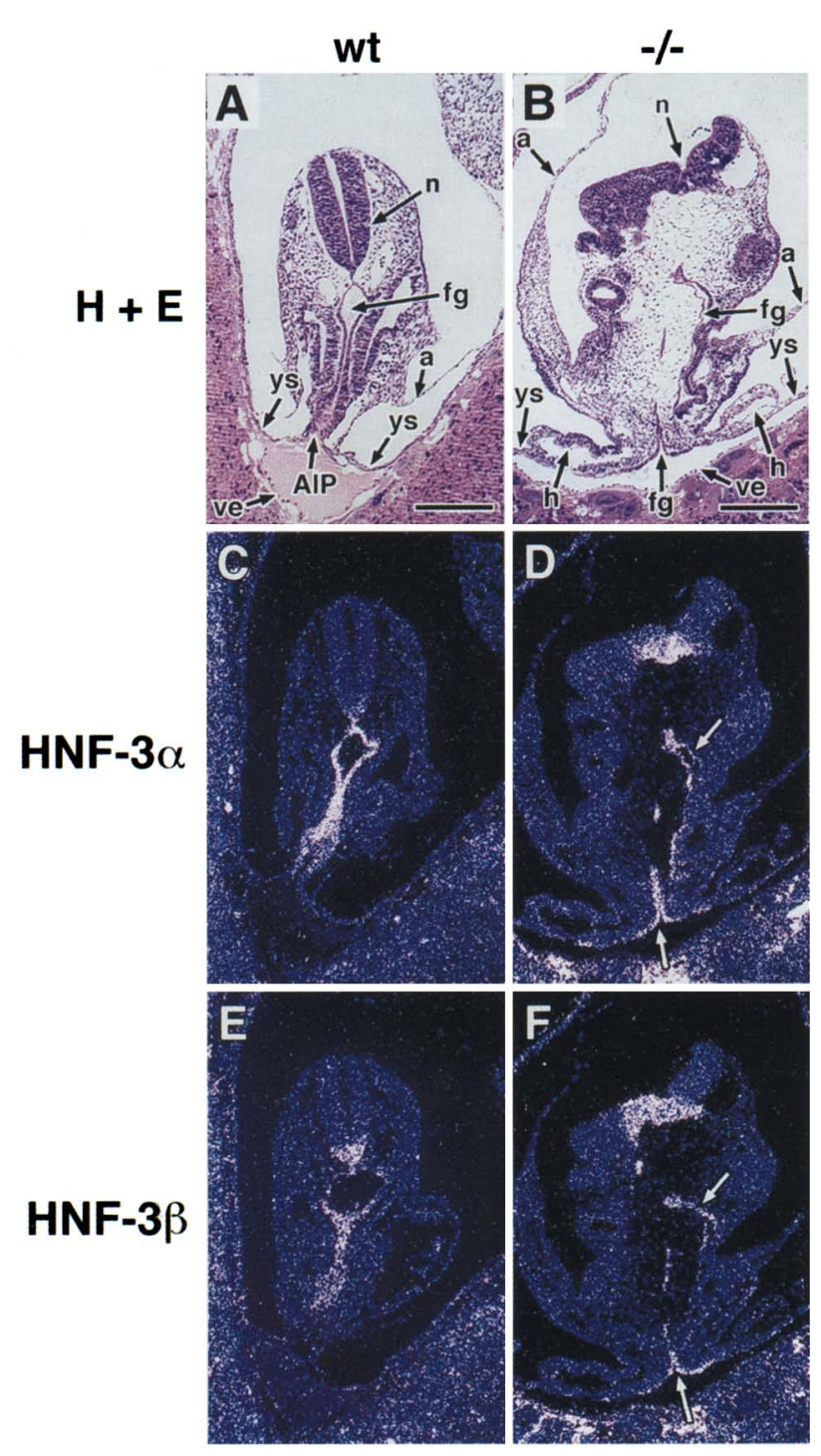

Figure 7. Gut formation in the $G A T A 4^{-/-}$embryo. Histological $(A, B)$ and in situ hybridization $(C-F)$ analyses of 9.0-dpc wild-type (wt) and 10.5-dpc GATA4 $4^{-1-}(-/-)$ embryos. $(A, B)$ $\mathrm{H} \& \mathrm{E}$-stained cross sections. (a) Amnion; (AIP) anterior intestinal pore; (fg) foregut; (h) heart; $(\mathrm{n})$ neural fold; (ve) visceral endoderm; (ys) yolk sac. The foregut of the $G A T A 4^{-1-}$ embryo is disorganized and slitlike and lacks a visible connection to the anterior pore. $(C, D)$ In situ hybridizations using an HNF3 $\alpha$ antisense cRNA probe. Note HNF3 $\alpha$ expression in the basal layer of the neural tube in both the wild-type and GATA4 ${ }^{-1-} \mathrm{em}$ bryos. $(E, F)$ In situ hybridizations using an HNF3 $\beta$ antisense cRNA probe. The arrows indicate disorganized foregut structures in the GATA4 ${ }^{-/-}$embryos. Bar, $125 \mu \mathrm{m}$.

the precardiac mesoderm results in a variety of cardiac morphogenic defects including the development of one or two laterally displaced cardiac structures (Osmond et al. 1991; Gannon and Bader 1995). These defects are

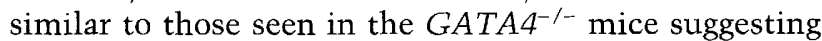
that the failure of migration and ventral fusion of the right and left coelomic cavities and splanchnic mesoderm may also contribute to the phenotype seen in the
GATA4 $4^{-1-}$ embryos. Such a model would also explain the observed morphogenic defects in the foregut and the failure of the yolk sac and amnion to envelop completely the ventral regions of the GATA4 $4^{-1-}$ embryos, as each of these events is dependent on the normal caudal and ventral migration of the lateral mesoderm (Moore and Persaud 1993; Kaufman 1995).

GATA4 expression is limited to the differentiating splanchnic mesoderm and the visceral endoderm at 7.0 $\mathrm{dpc}$ in the mouse embryo (Arceci et al. 1993; Heikinheimo et al. 1994). Therefore, it seems likely that the defect in rostral-to-caudal and lateral-to-ventral folding observed in the GATA4 ${ }^{-1-}$ embryos reflected either a cell-intrinsic defect in the proliferation or migration of the splanchnic mesoderm or a defect in a ventral morphogenic signal produced either by the splanchnic mesoderm itself or by the visceral endoderm. Thus, a critical question raised by our findings is whether the defect in cardiac development observed in the GATA4 ${ }^{-1-} \mathrm{em}$ bryos was intrinsic to the procardiomyocytes. Our finding that $\mathrm{GATA} 4^{-1-}$ cardiac myocytes populated the normal hearts of $G A T A 4^{-/-}-C 57 B L / 6$ chimeric mice demonstrated that the GATA4 ${ }^{-1-}$ procardiomyocytes do not have intrinsic defects in differentiation or migration and are competent to sense the morphogenic signals that regulate cardiac development. Therefore, these results suggested that the defect in heart tube formation seen in the $G A T A 4^{-/-}$embryos reflected defective morphogenic signals in these animals. The precise nature of these signals remains unclear. However, both soluble morphogens such as transforming growth factor- $\beta$ (TGF- $\beta$ ) and extracellular matrix proteins such as fibronectin have been postulated to play important roles in directing the migration of procardiomyocytes during heart development in amphibians and birds (Sugi et al. 1993; Sugi and Lough 1995; Linask and Lash 1988a,b). Thus, it is tempting to speculate that GATA4 may regulate the expression of such molecules either by the procardiomyocytes themselves or by the visceral endoderm that also expresses GATA4 at 7-8 dpc. Alternatively, it is possible that GATA4 is required for the production of secreted proteases that are needed for the normal ventral migration of procardiomyocytes.

\section{Potential functional redundancies of GATA4 and GATA6 during murine embryogenesis}

Three findings suggest that there may be important functional redundancies between GATA4 and GATA6 during cardiac development: (1) Both proteins are coexpressed developmentally in embryonic cardiac myocytes and endocardial cells (Laverriere et al. 1994; Morrisey et al. 1996); (2) both proteins can bind to and transactivate the same cardiac-specific promoters (Jiang and Evans 1996; Morrisey et al. 1996); and (3) GATA6 expression is increased in the GATA4 $4^{-/-}$embryos. Thus, it is possible that GATA6 can replace GATA4 in regulating the expression of contractile proteins and the differentiation of

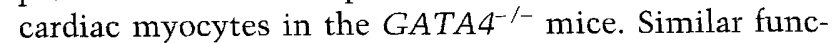
tional redundancies have been reported between mem- 

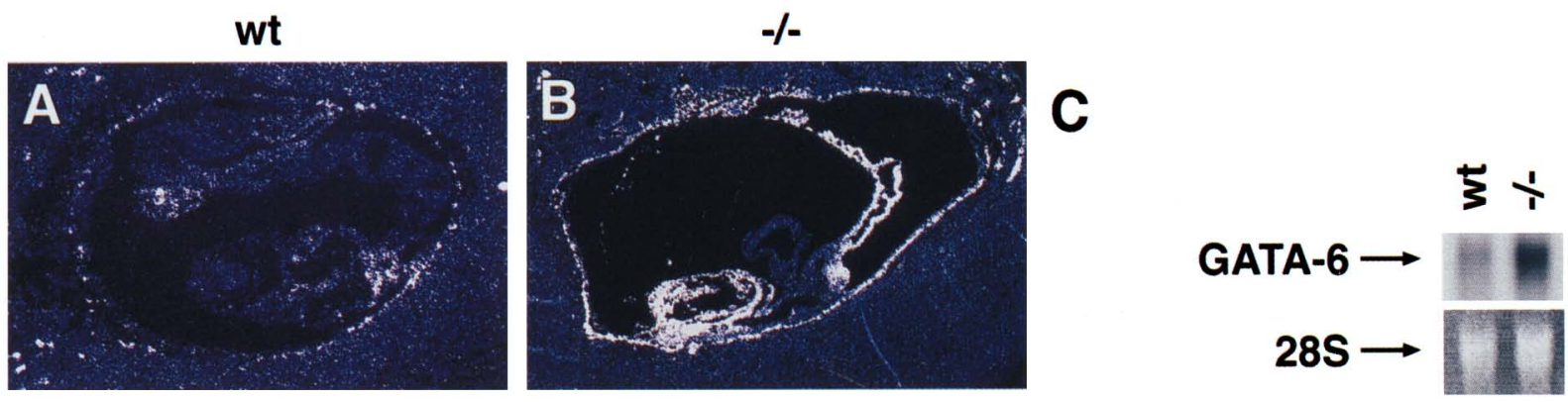

Figure 8. GATA6 expression in the $G A T A 4^{-/-}$embryo and embryoid bodies. $(A, B)$ In situ hybridizations to a 9.0-dpc wild-type (wt) and a 10.5-dpc GATA4 ${ }^{-/-}(-/-)$embryo using a GATA6 antisense cRNA probe. GATA6 expression is increased in the visceral endoderm and mutant heart of the $G A T A 4^{-/-}$embryo and is expressed aberrantly at high levels in the body wall of the $G A T A 4^{-/-}$ embryo. Identical photographic exposures of the wild-type and $G A T A 4^{-1-}$ embryos are shown. (C) (Top) Northern blot analysis of GATA6 expression in wild-type (wt) and GATA4 $4^{-1-}(-/-)$ embryoid bodies after 11 days of differentiation in vitro. (Bottom) Equal loading and integrity of the RNA samples was confirmed by ethidium bromide staining of the 28S RNA in the gel before transfer to nitrocellulose membranes (28S).

bers of the myogenic bHLH family of transcription factors (Rudnicki et al. 1993; Olson and Klein 1994; Wang et al. 1996). It appears less likely that GATA5 substitutes

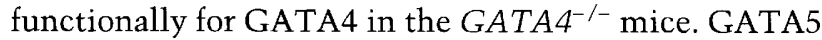
is not expressed normally in precardiac lateral plate mesoderm, is expressed only transiently in the embryonic heart tube, and is not expressed in adult cardiac myocytes (Morrisey et al. 1997). In addition, GATA5 expression becomes restricted to the atrial endocardium by $12.5 \mathrm{dpc}$ and GATA5 expression was not up-regulated in the $G A T A 4^{-/-}$embryos (data not shown). Functional redundancies between GATA4 and GATA6 may also occur in developing gut epithelium as both proteins are also coexpressed developmentally in this cell lineage.
Despite these potential functional redundancies, it is clear from the phenotype of the GATA4 ${ }^{-/-}$mice that GATA4 modulates unique morphogenic functions that cannot be replaced even by overexpression of GATA6.

The finding of increased GATA6 expression in the GATA4 ${ }^{-1-}$ embryos also suggested that there is significant cross-talk between these two closely related transcription factors. Thus, GATA4 appears to down-regulate directly or indirectly the expression of GATA6 in developing cardiac myocytes. A similar relationship has been observed previously between GATA1 and GATA2; GATA2 expression is increased in GATA1-deficient erythroid progenitors (Weiss et al. 1994). It is tempting to speculate that GATA6 might itself regulate GATA4 ex-

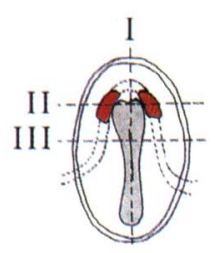

I
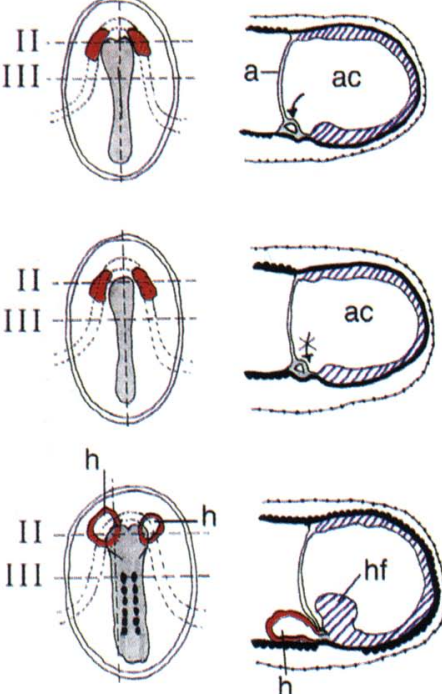

II
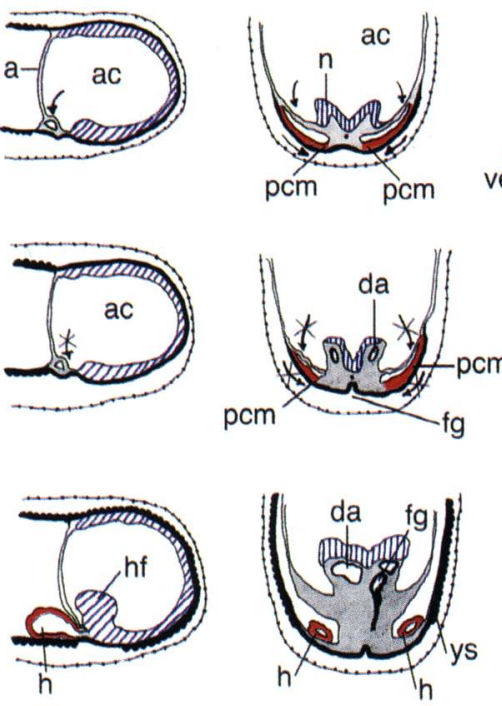

III
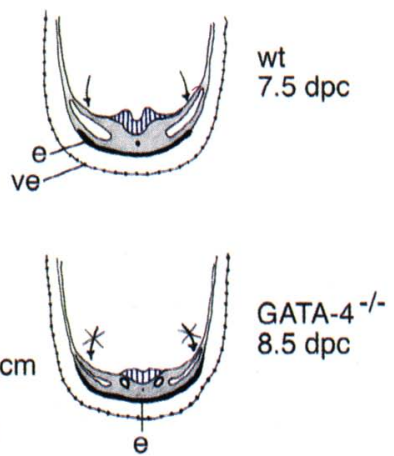

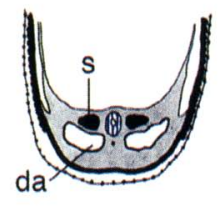

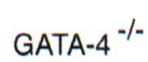
$10.5 \mathrm{dpc}$
Figure 9. Abnormal ventral morphogenesis and heart tube formation in GATA4 ${ }^{-1-}$ embryos. Schematic illustration comparing 7.5-dpc wild-type (wt) (top), and 8.5- (middle) and 10.5- (bottom) dpc GATA4 ${ }^{-/-}$embryos. (Left) Dorsal view of wt and $G A T A 4^{-1-}$ developing mouse embryos. (I) Sagittal sections of the same embryos. The wt and 8.5-dpc GATA4 ${ }^{-1-}$ embryos are shown as midline sections, whereas the 10.5-dpc GATA4 ${ }^{-/-}$embryo represents a lateral sagittal section. (II) Transverse sections through the same embryos at the level of the developing heart. (III) Transverse sections through the same embryos at the level of the developing foregut. The precardiac mesoderm and linear heart tube are shown in red, the somites are shown in solid black. The neural tube is shown by the vertical blue shading. (a) Amnion; (ac) amniotic cavity; (da) dorsal aorta; (e) embryonic endoderm; (fg) foregut; (h) heart; (hf) headfold; (n) neural fold; (pcm) precardiac mesoderm; (s) somite; (ve) visceral endoderm; (ys) yolk sac. Note the defective rostral-to-caudal and lateral-toventral folding of the GATA4 $^{-/-}$embryos $\left({ }^{*}\right)$, which results in the formation of aberrant cardiac structures in the anterior and lateral portion of the 10.5-dpc embryo as well as the lack of an organized AIP and foregut. 
pression positively and, as such, might be upstream of GATA4 during cardiac myocyte differentiation. It has been reported recently that overexpression of GATA6 in Xenopus embryos inhibits the expression of cardiac actin and myosin, leading to the suggestion that GATA6 is required for the maintenance of cardiomyocyte precursors (Gove et al. 1997). Interestingly, we did not observe inhibition of cardiac contractile protein expresson in the GATA4 ${ }^{-1-}$ embryos despite the fact that they over-express GATA6. This finding may reflect differences between frog and mouse cardiac development or differences in the experimental systems used in the two studies. In this light it will be of interest to study both cardiac development and GATA4 expression in GATA $6^{-1-}$ embryos, which are currently being generated in our laboratory. Finally, it is also of interest that GATA6 is expressed at high levels throughout the body of the $G A T A 4^{-1-}$ embryos, a location in which it is not normally expressed in wild-type embryos. This aberrant expression of GATA6 could contribute to the morphological defects seen in later stage $G A T A 4^{-1-}$ embryos.

\section{Materials and methods}

\section{Plasmids}

The lacZ expression vector contains the following fragments in the polycloning sites of pBluescript SK (Stratagene): base pairs 373-1561 of the human EF1 $\alpha$ promoter (Uetsuki et al. 1989) and the bacterial lacZ gene [base pairs 414-3820 of the pSV- $\beta$-galactosidase plasmid (Promega)] in the ClaI site; the bovine growth hormone poly-adenylation signal [base pairs 706-932 of pRc/ RSV vector (Invitrogen)] in the BamHI site; base pairs 1-463 of the murine 4F2 heavy chain first intron enhancer (Karpinski et al. 1989) in the NotI site; and a hygromycin-resistance cassette under the control of the mouse PGK promoter in the XhoI site. The construct was linearized with SalI before electroporation into ES cells. The construction of the GATA4 targeting vector has been described previously (Soudais et al. 1995; see Fig. 2A).

\section{Generation of $\mathrm{GATA}^{+/-}$and $\mathrm{GATA}^{-/-}$ES cells}

The GATA4 targeting construct was linearized with NotI before electroporation into R1 ES cells. Neomycin-resistant transfectants were selected by growth in G418 $(200 \mu \mathrm{g} / \mathrm{ml})$ and gancyclovir $(1 \mu \mathrm{M})$. DNA from ES cell clones was characterized by Southern blot analysis after NotI-XhoI digestion using a radiolabeled 1.2-kb EcoRI-XhoI genomic fragment probe from outside of the region of the targeting vector. GATA4 $4^{-1-}$ ES cells were obtained by subjecting independently derived GATA4 ${ }^{+/-}$ ES cell lines to increasing concentrations of G418 $(0.5,1$, and 2 $\mathrm{mg} / \mathrm{ml}$ ) as described previously (Mortensen et al. 1992).

\section{Generation of $\mathrm{GATA}^{-1-}$}

All animal experimentation was performed according to $\mathrm{Na}$ tional Institutes of Health (NIH) guidelines in the Franklin McLean Memorial Research Institute (FMI) animal facility of the University of Chicago. ES cells from three independently derived GATA4 ${ }^{+/-}$clones were microinjected into C57BL/6 donor blastocysts, which were implanted subsequently into CD1 pseudopregnant females (Bradley 1987). The resulting male chimeras were mated with C57BL/ 6 females and agouti offspring were genotyped by Southern blot analysis. One of the
GATA4 $^{+/-}$ES cell lines generated GATA4 $^{+/-}$heterozygous mice. These $G A T A 4^{+/-}$heterozygous mice were bred with C57BL/ 6 and CD1 animals to generate heterozygous $G A T A 4^{+/-}$ offspring that were interbred for phenotypic analysis.

Generation of $\beta$-gal ${ }^{+}-$GATA4 ${ }^{-/-}$ES cells and $\beta$-gal ${ }^{+}$ GATA4 ${ }^{-1-}-C 57 B L / 6$ chimeric embryos

Linearized lacZ expression vector was electroporated into GATA4 $^{-/-}$ES cells. After growth selection in hygromycin $(150$ $\mu \mathrm{g} / \mathrm{ml})$, resistant colonies were stained for $\beta$-gal expression. Independently derived $\beta$-gal ${ }^{+}-$GATA $4^{-1-}$ ES cell lines were microinjected into $\mathrm{C} 57 \mathrm{BL} / 6$ donor blastocysts that were implanted subsequently into CD1 pseudopregnant females (Bradley 1987). Embryos were harvested from pregnant females and stained with X-gal as described previously (Cheng et al. 1993).

\section{Northern blot analysis}

In vitro differentiation of ES cells was performed according to Doetschman et al. (1985). Differentiated ES cells were harvested after $0,1,4,11$, and 16 days of liquid culture. RNA was isolated using TRIzol reagent (GIBCO-BRL) according to the manufacturer's protocol and subjected to Northern blot analysis. Northern blots were probed with radiolabeled fragment from the $3^{\prime}$ untranslated region (base pairs 1678-1907) of the GATA4 cDNA or a probe from the $5^{\prime}$ coding region of the GATA6 cDNA (base pairs 590-1118).

\section{Histological and electron microscopic analyses}

Anesthetized pregnant female mice were perfused through the descending aorta with $4 \%$ paraformaldehyde in PBS to fix the embryos in utero. After removal from the mother and without any dissection, perfused embryos were fixed overnight at $4^{\circ} \mathrm{C}$ in $4 \%$ paraformaldehyde in PBS. After dehydration in increasing concentrations of ethanol $(50 \%, 70 \%, 95 \%$, and $100 \%)$, the embryos were transferred into xylene and embedded in paraffin before sectioning at $5 \mu \mathrm{m}$. Histological sections were stained with $\mathrm{H} \& \mathrm{E}$. For electron microscopic analyses, the $\beta$-galstained embryos were washed in PBS, then fixed in $2.5 \%$ glutaraldehyde in PBS at $4^{\circ} \mathrm{C}$ for $4 \mathrm{hr}$. After subsequent washes in PBS, the embryos were postfixed with $1 \%$ osmium tetroxide for $1 \mathrm{hr}$. After postfixation, the embryos were washed and stained with $1 \%$ uranyl acetate for $1 \mathrm{hr}$, washed with $0.2 \mathrm{M}$ maleate buffer ( $\mathrm{pH} 5.1)$, then dehydrated in increasing concentrations of ethanol. The dehydrated embryos were infiltrated directly and embedded with LK-112 medium. Ultrathin sections of the embedded embryos were cut with a diamond knife, mounted onto uncoated 200-mesh grids, and stained with uranyl acetate and lead citrate. Electron micrographs were made with a JEOL-CXII electron microscope operating at $80 \mathrm{kV}$.

\section{In situ hybridization}

In situ hybridizations using ${ }^{35} \mathrm{~S}$-labeled cRNA were performed as described previously (Kuratani et al. 1994; Morrisey et al. 1996). The cRNA probes used for in situ hybridizations were derived from cDNA templates obtained by RT-PCR using the following sets of primers: MHC sense $5^{\prime}$-GCCACTGATAGTGCCTTTGATGTG- ${ }^{\prime}$ ', antisense 5' -TCCTTCTTGTACTCCTCCTGCTCC-3'; MLC2A sense 5'-GCACAACGTGGCTCTTCTAATGTC-3', antisense 5'-CTGTCTACTCCTCTTTCTCATCCCC-3'; MLC2V sense 5'-TTGTTTGCCAAGAAGCGGATAGA- $3^{\prime}$, antisense 5'-GAACCTCTCTGCTTGTGTGGTCAG-3'; cTnC sense 5' -TGAGCTGTCTCCAGAATGGATGAC- 
3', antisense 5'-TCCGTAATGGTCTCACCTGTGGC-3'; cTnI sense 5'-GAAGCAGGAGATGGAACGAGAGG-3', antisense 5'-CGGTTTTCCTTCTCAATGTCCTC-3'; ANF sense 5'-AGTGGACTAGGCTGCAACAGCTTC-3', antisense 5'-ACACACCACAAGGGCTTAGGATC- ${ }^{\prime} ;$ Nkx 2.5 sense $5^{\prime}$-GACAGGAGCGACGGGCAGTTCTGC-3', antisense 5'-GCGCGTGGTCTCTCGGCGCCATCC-3'; AFP sense 5'-GTGCTTCCAGACAAAGAGAGCATC- $3^{\prime}$, antisense $5^{\prime}$-CTGAGACAGGAAGGTTGGGGTGAG-3'; HNF3 $\alpha$ sense 5 '-CTCAGCTGCATCTGAAAGGGGATCC- 3 ', antisense $5^{\prime}$-CTCCTGCTACCAGGTTGGCCATGC- $3^{\prime}$; HNF3 $\beta$ sense $5^{\prime}$-GTCACTGGGGACAAGGGAAATGAG-3', antisense 5'-CTTTCTCCTGGTCCGGTACACC-3'; HNF4 sense 5'-GAGCCATCACCACCATCGTCAAGC-3', antisense 5'-GAGTCCAGGCAGTGGAAGACAGTC-3:

Adult heart RNA was used as the source for RT-PCR of MHC, MLC2A, MLC2V, cTnC, cTnI, and ANF. The cDNAs of $\mathrm{AFP}, \mathrm{HNF} 3 \alpha, \mathrm{HNF} 3 \beta$, and HNF4 were derived from day 11 in vitro-differentiated ES cell RNA. The in situ hybridization probe for $\mathrm{Nkx} 2.5$ was derived from an $\mathrm{Nkx} 2.5 \mathrm{cDNA}$ contained in pBluescript. GATA4 and GATA6 cDNA templates used for in situ hybridization were described previously (Morrisey et al. 1996). Histological sections and dark-field photomicrographs were made with a Zeiss Axioskop.

\section{Acknowledgments}

We thank C. Clendenin for technical assistance with the preparation of chimeric mice; $M$. Veselits, J. Grushcow, and H. Ip for technical assistance with in situ hybridization; R. Fentzke and $\mathrm{H}$. Lin for technical assistance with profusion fixation; S. Izumo for providing us with the $\mathrm{Nkx} 2.5 \mathrm{cDNA}$; E. Olson and J. Molkentin for sharing their unpublished data on independently derived GATA4-deficient mice; P. Lawrey and L. Gottschalk for help with the preparation of the manuscript and illustrations; and E. McNally and M.C. Simon for helpful discussions. This work was supported by NIH grants HL54592 to J.M.L. and HL51145 to M.S.P.

The publication costs of this article were defrayed in part by payment of page charges. This article must therefore be hereby marked "advertisement" in accordance with 18 USC section 1734 solely to indicate this fact.

\section{References}

Arceci, R.J., A.A. King, M.C. Simon, S.H. Orkin, and D.B. Wilson. 1993. Mouse GATA4: A retinoic acid-inducible GATA binding transcription factor expressed in endodermally derived tissues and heart. Mol. Cell. Biol. 13: 22352246.

Bodmer, R. 1993. The gene tinman is required for specification of the heart and visceral muscles in Drosophila. Development 118: 719-729.

Bradley, A. 1987. Production and analysis of chimaeric mice. In Tetratocarcinomas and embryonic stem cells, a practical approach (ed. E.J. Robertson), pp. 113-151. IRL Press, Oxford, UK.

Cheng, T.C., M.C. Wallace, J.P. Merlie, and E.N. Olson. 1993. Separable regulatory elements governing myogenin transcription in mouse embryogenesis. Science 261: 215-218.

Crossley, M., M. Merika, and S.H. Orkin. 1995. Self-association of the erythroid transcription factor GATAl mediated by its zinc finger domains. Mol. Cell. Biol. 15: 2448-2456.

DeRuiter, M.C., R.E. Poelmann, I. VanderPlas-de Vries, M.M.
Mentink, and A.C. Gittenberger-de Groot. 1992. The development of the myocardium and endocardium in mouse embryos. Anat. Embryol. 185: 461-473.

Doetschman, T.C., H. Eistetter, M. Katz, W. Schmidt, and R. Kelmer. 1985. The in vitro development of blastocyst-derived embryonic stem cell lines: Formation of visceral yolk sac, blood islands, and myocardium. J. Embryol. Exp. Morphol. 87: 27-45.

Dorfman, D.M., D.B. Wilson, G.A.P. Bruns, and S.H. Orkin. 1992. Human transcription factor GATA2: Evidence for regulation of preproendothelin-1 gene expression in endothelial cells. I. Biol. Chem. 267: 1279-1285.

Evans, T. and G. Felsenfeld. 1989. The erythroid-specific transcription factor eryf1: A new finger protein. Cell 58: 877885.

Gannon, M. and D. Bader. 1995. Initiation of cardiac differentiation occurs in the absence of anterior endoderm. Development 121: 2439-2450.

Gove, C., M. Walmsley, S. Nijjar, D. Bertwistle, M. Guille, G. Partington, A. Bomford, and R. Patient. 1997. Over-expression of GATA6 in Xenopus embryos blocks differentiation of heart precursors. EMBO J. 16: 355-368.

Grepin, C., L. Dagnino, L. Robitaille, L. Haberstroh, T. Antakly, and M. Nemer. 1994. A hormone-encoding gene identifies a pathway for cardiac but not skeletal muscle gene transcription. Mol. Cell. Biol. 14: 3115-3129.

Grepin, C., L. Robitalille, T. Antakly, and M. Nemer. 1995. Inhibition of transcription factor GATA4 expression blocks in vitro cardiac muscle differentiation. Mol. Cell. Biol. 15: 4095-4102.

Heikinheimo, M., J.M. Scandrett, and D.B. Wilson. 1994. Localization of transcription factor GATA4 to regions of the mouse embryo involved in cardiac development. Dev. Biol. 164: 361-373.

Ho, I.C., P. Vorhees, N. Marin, B.K. Oakley, S.F. Tsai, S.H. Orkin, and J.M. Leiden. 1991. Human GATA3: A lineage-restricted transcription factor that regulates the expression of the T cell receptor alpha-gene. EMBO I. 10: 1187-1192.

Ip, H.S., D.B. Wilson, M. Heikinheimo, Z. Tang, C.N. Ting, M.C. Simon, J.M. Leiden, and M.S. Parmacek. 1994. The GATA4 transcription factor transactivates the cardiac muscle-specific troponin $C$ promoter-enhancer in nonmuscle cells. Mol. Cell. Biol. 14: 7517-5126.

Jiang, Y. and T. Evans. 1996. The Xenopus GATA4/5/6 genes are associated with cardiac specification and can regulate cardiac-specific transcription during embryogenesis. Dev. Biol. 174: 258-270.

Karpinski, B.A., L.H. Yang, P. Cacheris, G.D. Morle, and J.M. Leiden. 1989. The first intron of the 4F2 heavy-chain gene contains a transcription enhancer element that binds multiple nuclear proteins. Mol. Cell. Biol. 9: 2588-2597.

Kaufman, M.H. 1995. Early stages in the development of the heart. In The atlas of mouse development, revised edition (ed. M.H. Kaufman), pp. 439-444. Academic Press, London, UK.

Kaufman, M.H. and V. Navaratnam. 1981. Early differentiation of the heart in mouse embryos. J. Anat. 133: 235-246.

Kelley, C., H. Blumberg, L.I. Zon, and T. Evans. 1993. GATA4 is a novel transcription factor expressed in endocardium of the developing heart. Development 118: 817-827.

Ko, L.J. and J.D. Engel. 1993. DNA-binding specificities of GATA transcription factor family. Mol. Cell. Biol. 13: 40114022.

Ko, L.J., M. Yamamoto, M.W. Leonard, K.M. George, P. Ting, and J.D. Engel. 1991. Murine and human T-lymphocyte GATA3 factors mediate transcription through a cis-regula- 
tory element within the human T-cell receptor delta gene enhancer. Mol. Cell. Biol. 11: 2778-2784.

Komuro, I. and S. Izumo. 1993. Csx: A murine homeobox-containing gene specifically expressed in the developing heart. Proc. Natl. Acad. Sci. 90: 8145-8149.

Kuratani, S., J.F. Martin, S. Wawersik, B. Lilly, G. Eichele, and E.N. Olson. 1994. The expression pattern of the chick homeobox gene MHox suggests a role in patterning of the limbs and face and in compartmentalization of somites. Dev. Biol. 161: 357-369.

Laverriere, A.C., C. MacNeill, C. Mueller, R.E. Poelmann, J.B. Burch, and T. Evans. 1994. GATA4/5/6, a subfamily of three transcription factors transcribed in developing heart and gut. J. Biol. Chem. 269: 23177-23184.

Lee, M.E., D.H. Temizer, J.A. Clifford, and T. Quertermous. 1991. Cloning of the GATA binding protein that regulates endothelin-1 gene expression in endothelial cells. J. Biol. Chem. 266: 16188-16192.

Linask, K.K. and J.W. Lash. 1988a. A role for fibronectin in the migration of avian precardiac cells: I. Dose-dependent effects of fibronectin antibody. Dev. Biol. 129: 315-324.

1988b. A role for fibronectin in the migration of avian precardiac cells: II. Rotation of the heart-forming region during different stages and its effects. Dev. Biol. 129: 325-329.

Lints, T.J., L.M. Parsons, L. Hartley, I. Lyons, and R.P. Harvey. 1993. Nkx2.5: A novel murine homeobox gene expressed in early heart progenitor cells and their myogenic descendants. Development 119: 419-431.

Lyons, I., L.M. Parsons, L. Hartley, R. Li, J.E. Andrews, L. Robb, and R.P. Harvey. 1995. Myogenic and morphogenetic defects in the heart tubes of murine embryos lacking the homeo box gene Nkx2-5. Genes \& Dev. 9: 1654-1666.

Merika, M. and S.H. Orkin. 1993. DNA-binding specificity of GATA family transcription factors. Mol. Cell. Biol. 13: 3999-4010.

Molkentin, J.D., D.V. Kalvakolanu, and B.E. Markham. 1994. Transcription factor GATA4 regulates cardiac muscle-specific expression of the alpha-myosin heavy-chain gene. Mol. Cell. Biol. 14: 4947-4957.

Moore, K.L. and T.V. Persaud. 1993. Development of tissues, organs, and body form. In The developing human (ed. K.L. Moore and T.V. Persaud), pp. 70-92. W.B. Saunders, Philadelphia, PA.

Morrisey, E.E., H.S. Ip, M.M. Lu, and M.S. Parmacek. 1996. GATA6: A zinc finger transcription factor that is expressed in multiple cell lineages derived from lateral mesoderm. Dev. Biol. 177: 309-322.

Morrisey, E.E., H.S. Ip, Z. Tang, M.M. Lu, and M.S. Parmacek. 1997. GATA5: A transcriptional activator expressed in a novel temporally and spatially-restricted pattern during embryonic development. Dev. Biol. 183: 21-36.

Mortensen, R.M., D.A. Conner, S. Chao, A.A. Geisterfer-Lowrance, and J.G. Seidman. 1992. Production of homozygous mutant ES cells with a single targeting construct. Mol. Cell. Biol. 12: 2391-2395.

Olson, E.N. and W.H. Klein. 1994. bHLH factors in muscle development: Dead lines and committments, what to leave in and what to leave out. Genes \& Dev. 8: 1-8.

Olson, E.N. and D. Srivastava. 1996. Molecular pathways controlling heart development. Science 272: 671-676.

Osmond, M.K., A.J. Butler, F.C. Voon, and R. Bellairs. 1991. The effects of retinoic acid on heart formation in the early chick embryo. Development 113: 1405-1417.

Pevny, L., M.C. Simon, E. Robertson, W.H. Klein, S.F. Tsai, V. Dagati, S.H. Orkin, and F. Constantini. 1991. Erythroid differentiation in chimeric mice blocked by a targeted muta- tion in the gene for transcription factor GATA1. Nature 349: $257-260$.

Rotter, M., K. Zimmerman, A. Poustka, Y.N. Soussi, and P.A. Starzinski. 1991. The human embryonic myosin alkali light chain gene: Use of alternative promoters and 3' non-encoding regions. Nucleic Acids Res. 19: 1497-1504.

Rudnicki, M.A., P.N. Schnegelsberg, R.H. Stead, T. Braun, H.H. Arnold, and R. Jaenisch. 1993. MyoD or Myf-5 is required for the formation of skeletal muscle. Cell 75: 1351-1359.

Simon, M.C. 1995. Gotta have GATA. Nature Genet. 11: 9-11. Soudais, C., M. Bielineka, M. Heikinheimo, C.A. MacArthur, N. Narita, J.E. Saffitz, M.C. Simon, J.M. Leiden, and D.B. Wilson. 1995. Targeted mutagenesis of the transcription factor GATA4 gene in mouse embryonic stem cells disrupts visceral endoderm differentiation in vitro. Development 121: $3877-3888$.

Srivastava, D., P. Cserjesi, and E.N. Olson. 1995. A subclass of bHLH proteins required for cardiac morphogenesis. Science 270: 1995-1999.

Sugi, Y. and J. Lough. 1995. ActivinA and FGF-2 mimic the inductive effects of anterior endoderm on terminal cardiac myogenesis in vitro. Dev. Biol. 168: 567-574.

Sugi, Y., J. Sasse, and J. Lough. 1993. Inhibition of precardiac mesoderm cell proliferation by antisense oligodeoxynucleotide complementary to fibroblast growth factor 2 (FGF-2). Dev. Biol. 157: 28-37.

Ting, C.N., M.C. Olson, K.P. Barton, and J.M. Leiden. 1996. Transcription factor GATA3 is required for development of the T-cell lineage. Nature 386: 474-478.

Tsai, F.Y., G. Keller, F.C. Kuo, M. Weiss, J. Chen, M. Rosenblatt, F.W. Alt, and S.H. Orkin. 1994. An early haematopoietic defect in mice lacking the transcription factor GATA2. $\mathrm{Na}$ ture 371: 221-226.

Tsai, S.F., D.I. Martin, L.I. Zon, A.D. D'Andrea, G.G. Wong, and S.H. Orkin. 1989. Cloning of cDNA for the major DNA binding protein of the erythroid lineage through expression in mammalian cells. Nature 339: 446-451.

Uetsuki, T., A. Naito, S. Nagata, and Y. Kaziro. 1989. Isolation and characterization of the human chromosomal gene for polypeptide chain elongation factor 1-alpha. J. Biol. Chem. 264: 5791-5798.

Wang, Y., P.N. Schnegelsberg, J. Dausman, and R. Jaenish. 1996. Functional redundancy of the muscle-specific transcription factors Myf5 and myogenin. Nature 379: 823-825.

Weiss, M.J., G. Keller, and S.H. Orkin. 1994. Novel insights into erythroid development revealed through in vitro differentiation of GATA1 embryonic stem cells. Genes \& Dev. 8: 1184-1197. 


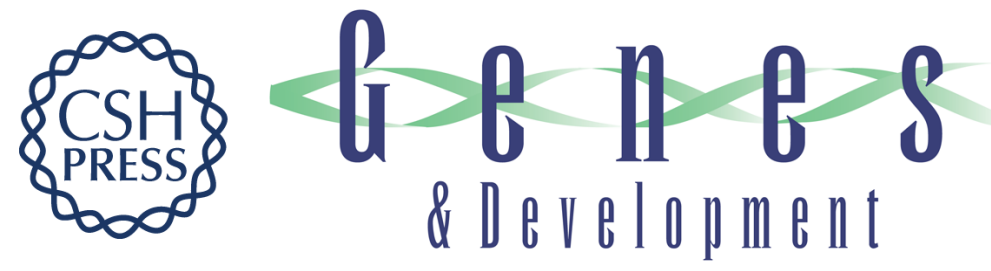

\section{GATA4 transcription factor is required for ventral morphogenesis and heart tube formation.}

C T Kuo, E E Morrisey, R Anandappa, et al.

Genes Dev. 1997, 11:

Access the most recent version at doi:10.1101/gad.11.8.1048

References This article cites 50 articles, 27 of which can be accessed free at:

http://genesdev.cshlp.org/content/11/8/1048.full.html\#ref-list-1

License

Email Alerting

Service

Receive free email alerts when new articles cite this article - sign up in the box at the top right corner of the article or click here.

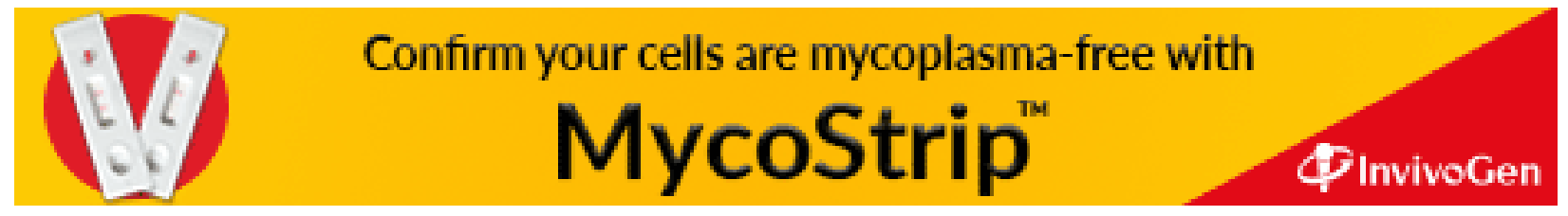

